\title{
A Route to Safety: Using bus boarding data to identify roles for transport providers
} within contextual safeguarding systems - Accepted for Publication

\begin{abstract}
During adolescence, risk to young people's safety shifts from familial to community contexts. Contextual safeguarding has emerged in response to this dynamic; by providing a conceptual framework through which practitioners can incorporate extra-familial contexts (and those who manage them) into traditionally family-focused child protection systems. , This paper uses GiS mapping techniques to explore the extent to which bus boarding data could be used to: target protective interventions in public spaces; evidence routes where young people may be vulnerable; and build local area problem profiles. In doing so it provides foundational evidence for including transport providers in contextual safeguarding systems.
\end{abstract}

\section{Introduction}

As individuals move from early childhood into adolescence they become increasingly vulnerable to abuse in community contexts (Author A, 2017; Coleman, 2011; Sidebotham, et al., 2016; Smallbone, et al., 2013); a dynamic requiring safeguarding partnerships to identify opportunities for assessing and intervening with risks that percolate in social and public contexts. This is a challenge - given that child protection and safeguarding practices are primarily focused on risk within families (Author A, 2017; Parton, 2014). This paper uses the results of exploratory tests with bus-related travel data in London to consider the contribution that transport providers could make to developing more contextual responses to adolescent safeguarding following policy scrutiny regarding young people's experiences of abuse and exploitation on transport networks (Transport Select Committee, 2014).. Viewed through the conceptual lens of contextual safeguarding (Author A et al. 2016), results suggest that there is much promise in including transport providers, and the travel data that they hold, in local multi-agency safeguarding practices. Should the methodologies and data used in this paper be applied to local practice, partnerships may be better placed to proactively: identify and task interventions into public spaces, and at times, when they are mostly used by young people; evidence when and where young people may be vulnerable late at night and during the school day; and triangulate transport data with existing community safety, social care and policing data to fill knowledge gaps about public space risk and confirm knowledge of some existing patterns.

Young people's experiences of public-space violence and abuse

As young people move into adolescence they spend increasing time socialising beyond their family home (Catch 22, 2013; Coleman, 2011). As they build relationships independently of their families, travel to school without parental supervision, engage in extra-curricular activities and sometimes part-time employment, their parents and carers have less influence over the nature of the spaces in which they spend their time (Author A, 2017; Aldridge, et al., 2011; Parton, 2014). Meta-reviews of cases in which young people experienced significant harm in the UK evidence a shift from risk in the home to risk in the community at this time ( : 
among younger children the incidents occurred almost exclusively within a family setting...In later adolescence, however, the pattern is reversed, with the majority of incidents (both fatal and non-fatal) occurring outside of the family (Sidebotham, et al., 2016: 45)

Young people experience a range of abusive behaviours in public spaces (Barter, 2009;; Smallbone, et al., 2013; Squires \& Goldsmith, 2011). When the crime survey was extended to include young people (under-16) in England and Wales responses indicated that they experienced 465,000 incidents of violent crime in a year - the majority of which occurred in public places such as robbery accompanied with physical violence or the use of weapons (Office of National Statistics, 2013). . Young people growing up in gang-affected neighbourhoods have described their experiences of violence when spending time on the streets - accounts in-keeping with the experiences of young people in other Western countries have been exposed to crime in public spaces during adolescence (Anderson, 1999; World Health Organisation, 2014):

whilst it appeared loving, protecting, cool and the "in thing to do", actually it was nothing but misery. Having to be ... . constantly paranoid about your own safety ... and nothing but torture and hell (Catch 22, 2013, p. 51)

). Young people also encounter sexual violence in public contexts (Firmin, 2017; Hackett, 2014; Smallbone, et al., 2013). Young people have been sexually exploited in parks, shopping centres, fast food restaurants and hotels. Adults have frequented these places to groom and abuse young people, and used transport hubs and car services to meet and transport those they abuse (D'Arcy \& Thomas, 2016; Hughes-Jones \& Roberts, 2015). This is in addition to peer-on-peer sexual abuse occurring between young people as they socialise the public spaces (Author A, 2017; Beckett, et al., 2013).

Parents are unable to shape the physical and cultural nature of many community contexts: Young people socialise in public spaces without their parents; parents cannot control the nature of these environments, and their influence is often outweighed by the peer social norms that manifest in these contexts during adolescence (Barter, 2009; Firmin, 2017; Warr, 2002). . As such, questions arise as to which adults or professionals, if any, are equipped and able to safeguard young people from harm in public places. Over recent years in the UK community organisations, police and children's social care services have trained staff who work in the night-time economy, shopping centres and transport providers to be alert to the signs of sexual exploitation in recognition of the potential for professionals who deliver these services to safeguard young people who they encounter. Transport providers in particular have come under increased scrutiny by policymakers in this regard. In 2014 the Transport Select Committee of the UK Government argued that more action was required by transport providers and transport police to safeguard vulnerable young people who were at risk in stations when running away from home (Transport Select Committee, 2014). Following inquiries into child sexual exploitation in which some young people were trafficked across the country by taxi, some local councils required taxi drivers to undertake safeguarding training as a condition of licence renewal (Lynn News, 2016). And in 2016 Transport for London established a safeguarding board to review and improve the extent to which they kept young people and vulnerable adults safe on its network. This paper contributes knowledge to 
inform these activities, by exploring the potential use of travel data to safeguard young people from harm on the bus network.

\section{Young people's safety onpublic transport}

Despite limited research in the area, transport networks have been identified through case reviews and inquiries (Author A, 2015, Transport Select Committee, 2014) as locations in which young people might encounter safeguarding issues, such as those noted above. Transport crime is concentrated at a small proportion of stops, stations or hubs (Newton, 2014), however, and so safeguarding issues faced by young people may be similarly concentrated at certain stops or route segments - which if identified could be targeted with interventions.

In London, young people can travel for free on the bus network through use of the Zip Oyster photocard - a smart travel card offering unrestricted free travel on buses to young people (Tfl, 2016a). The impact of free bus travel for young people through the use of the Zip Oyster photocard from 2007 onwards in London has been the primary focus of research in this area. The universality of free travel is thought to have benefitted young people in terms of advancing social mobility and enabling equal access to services (Jones, 2010; Goodman et al., 2014). It also appears that beyond a means of transport young people are using the bus network as a social space: more time is being spent by young people on buses as a result of it being free Jones et al. (2013) bus travel has become a 'lowest common denominator' of travel mode choices, with 'bus-hopping' and long journeys commonplace amongst young people Goodman et al. (2014).

Although young people appear to be using buses as a social space, the bus network is also location in which they have reported feeling most vulnerable. Young Londoners are more likely than other age groups to travel with someone else for safety (Burton, 2008; TfL, 2015). Safety concerns relate particularly to the numbers of young people (increase in potential perpetrators and victims), the convergence of different groups on buses (different schools meeting on the network) and the anonymity the bus network affords (Burton, 2008; Newton et al., 2014).Whilst the concerns about young people's safety on the transport network are clear, the implications of this for safeguarding policy and practice requires far more consideration - a matter upon which this paper is focused.

\section{Methodology}

Whilst the findings of this paper are relevant to transport providers in general, this research focusses on, and uses data provided by, Transport for London ( $T f L)$. TfL's bus network is one of the most extensive in the world, carrying over 2 billion passengers in 2015/16 (TfL, $2016 b$ ), across 675 routes (TfL, 2016c). A large proportion of the two million young people in London travel for free on London's bus network using 'Zip' cards (GLA Intelligence, 2012). The data generated by these cards provides a source of information for better identifying the places and routes where young people spend their time. Information which could inform the work of multi-agency partnerships who are seeking to identify contexts in which young people are vulnerable to harm (Author A and Anon 2018, forthcoming)

Theoretical framework: Contextual Safeguarding 
'Contextual safeguarding' has been developed in recognition of the risks that young people encounter in extra-familial contexts, the limited influence that parents and carers have in these situations, and the traditionally family-focused lens of child protection frameworks (Author A, 2015; Author A et al., 2016; Author A, 2017). The theory uses the sociological concepts of social field, habitus and capital introduced by Pierre Bourdieu (1990), and draws upon learning from multi-systemic therapy and situational crime prevention and (i.e. Smallbone, et al., 2013) to explore and articulate the relaitonship/s between individual agency, childhood dependency and the rules at play within the different (and partiuclarly extra-familial) social contexts in which young people encounter abuse.

Scholars such as Powell (2010) have used Bourdieu's sociological lens to demonstrate the ways in which this relationship between social rules and individual agency has facilitated the embodiment of abusive norms within young people's relationships - and contextual safeguarding understands abuse in the same way. According to contextual safeguarding theory young people are social agents who engage with a range of familial and extra-familia social fields. Each of these fields feature social rules which shape, and are shaped by, the behaviours of young people, their peers, and other adults who are engaged with, and sometimes manage, these fields. On occasion the rules/norms within these social fields can permit, facilitate or fail to challenge abusive behaviours.

Upon entering a social field, such as their local park, school or shopping centre, young people draw upon their capital (social, economic, cultural and symbolic) to engage in the rules of that field, and through a process of embodiment construct, and are constructed by, it. Other adults and young people who use said fields are also engaged in this process of social rule (re)construction, as are those who manage/design these spaces. In the case of a park these may be park wardens, gardeners, and community safety practitioners; in schools they would be governors, teachers, education policymakers, pastoral staff etc.; and in shopping centres security officers, CCTV monitors, store managers and so on. All of these social actors contribute to the rules in extra-familial social spaces in which parents have little influence. As a result young people are dependent upon a range of individuals who influence the rules at play within extra-familial settings in which they may encounter abuse.

In recognition of these contextual dynamics of abuse, social care services have drawn upon contextual safeguarding to form partnerships with agencies that are better positioned to influence the nature of extra-familial settings in which young people encounter harm, but which are traditionally beyond the remit of child protection (Author A et al. 2016). This work adapts and extends the reach of child protection systems that have primarily focused on families, to recognise how the nature of extra-familial spaces can undermine the capacity of parents to keep their children safe and challenge parameters of individualised social work models across the world (Liebenberg, et al., 2015; Parton, 2014;).

Given the limited reach of familial social work what, if any, role could transport providers play in bridging this gap between extra-familial risk and child protection structures? In this paper the authors have used contextual safeguarding theory as the rationale for an exploratory study into the use of bus travel data as a mechanism through which transport providers could contribute to the safeguarding assessments, profiles and interventions. Could transport data: direct preventative interventions and add to multi-agency profiles of risk in local areas? If so then there is an opportunity to involve transport providers within contextual 
safeguarding systems, and respond to emerging concerns about the welfare of young people in extra-familial spaces.

\begin{abstract}
Dataset
Zip Oyster photocard data was provided by TfL for the period $12^{\text {th }}$ June to $9^{\text {th }}$ July 2016 . The data provided was an aggregate count of boardings made using a Zip card at an individual bus stop during 60-minute intervals, extracted by the data providers as a csv file - a simple file format which stores tabular data for use in software such as Microsoft Excel. Following consultation with $\mathrm{TfL}$ data privacy professionals, it was decided that aggregate counts of Zip boardings totalling less than ten would be omitted from the data provided (i.e. the total of Zip boardings by bus stop and hour intervals had to equal ten or more), to ensure anonymity. In order to assess the implication of this, TfL provided a full count of all Zip boardings during the time period $(21,774,061)$. The aggregate data provided totalled $11,502,690$ boardings, meaning the omission of aggregate counts fewer than ten excluded $47 \%$ of Zip boardings from the analysis here. TfL also provided bus stop IDs and their coordinates so that the zip boarding data could be used within a Geographic Information System (ArcGIS 10.3) for the purposes of spatial analysis - the analysis of spatial data within a mapping environment (de Smith et al., 2007). This allowed the researchers to visualise, as well as analyse Zip travel patterns.
\end{abstract}

\title{
Approach to analysis
}

Data was analysed using techniques from the field of Geographic Information Science (GIS). As the data was joined to a bus stop layer within ArcGIS 10.3 software, it was possible to apply a range of spatial analysis techniques to the data in order to identify its potential use for informing agencies of possible safety and/or safeguarding issues on the bus network. Additionally, as decisions within transport environments are often made at the road segment level, Zip boarding counts were joined to the OpenStreetMap (OSM) road network layer..

Within ArcGIS, a range of visualisations were generated focussing on varying spatial and temporal extents (i.e. LA level, pan-London level, AM or PM peak hours). Analysis and visualisation techniques utilised include: choropleth maps, Inverse Distance Weighted (IDW) interpolation and the classification of Zip boarding totals at bus stop or road segment level with sequential colour ramps applied (de Smith et al., 2007). These processes were repeated on multiple occasions to identify variations in travel between bus stops, road segments and local authorities at different times. Each of the different map visualisation techniques used enabled an understanding of the previously unknown spatial distribution and concentration of Zip boardings within Greater London. The resulting visualisations were saved and utilised for interpretation of findings in relation to the potential to improve the identification of, and response to, safeguarding issues on the bus network.

\section{Ethics and Limitations}

This study was approved via the ethics processes within TfL. Particular consideration was given to the anonymity of individuals on the bus network and data protection. All published findings do not name local authorities or locations associated with the data, with the 
exception of a pan-London map visualisation. As noted previously, access was only provided to aggregate counts of Zip boardings by bus stop and 60-minute interval which, while limiting the study, was all that was required for its exploratory objective. An additional limitation is that Zip cards are only 'touched in' at the start of a journey meaning that only bus journey origins (rather than destinations) are known (Bagchi and White, 2005; Smith et al., 2013). The travel patterns presented are also only those of young people who own and use a Zip card. It is possible that some young people use buses but do not have access to a Zip cardincluding for reasons that increase their vulnerability such as it being stolen by peers. Ideally such young people would feature in a study such as this but given the data collection method they are missing from the sample.

The ethics of using travel data in the way proposed in this study also required/s consideration. There is a risk that using data in this way could increase surveillance of young people and infringe upon their rights to privacy. It is for this reason that, at this stage, the study explored the potential of the data only. However, if methodologies tested here were explored elsewhere further consideration would be required to ensure that all partners used the data for the purposes of safeguarding young people at risk of significant harm. More specifically, contextual safeguarding would require that data was used to identify, target interventions at, and create contexts in which young people can socialise $=$ rather than to track and control the actions of individual young people.

\section{Findings}

This study found that Zip card data can be used to identify:

- $\quad$ The times and places where young people use the bus network at a Pan-London level

- Patterns of travel within local authorities to identify travel corridors and bus stops where young people converge and may cross local authority boundaries

- That some young people are travelling from unexpected locations at unusual times of day/night which could indicate safeguarding concerns

Each of these findings will be outlined in turn. When taken together, and viewed within a contextual safeguarding lens, they suggest that Zip card data could be utilised by multiagency partnerships to both confirm and extend how they identify extra-familial contexts in which young people socialise, and may on occasion be at risk. . While knowing about travel patterns alone is insufficient to identify safeguarding concerns, should the methodologies presented in this paper be built into the work of safeguarding partnerships they could point towards contextual sites for assessment and intervention.

\section{The Pan-London potential of transport data}


As Zip card data had not been accessed in this way before, it was important to firstly explore what the data could tell us about the times (temporal analysis) and the places (spatial analysis) where young people used the bus network .

During weekdays young people's travel on the bus network peaked during the hours of 07:00-08:59 and 15:00-16:59 (Figures 1 and 2), but made almost 50\% more journeys in the afternoon than in the morning time - suggesting that in the morning they may just travel from home to school but in the afternoons other journeys may be taking place. Comparatively Zip boarding totals during weekends were more evenly distributed throughout the day, peaking from 12:00-18:59.

\section{INSERT FIGURE 1}

\section{INSERT FIGURE 2}

In addition to producing these somewhat expected results, analysis of both weekday and weekend travel showed that although proportionally small, Zip boardings were made during night time hours (22:00-05:00). These had the potential to be missing young people(D'Arcy et al. 2016) and required further investigation . Furthermore, young people appear to be making a large number of journeys on weekdays during core school hours, when one would not expect them to be accessing the bus network. While this can be partly explained by some Zip cards being held by those who are above compulsory school age or who attend college without fixed timetables, potential questions also arise about truancy patterns.

Spatial analysis of Zip card data also provided information about where young people are spending their time on buses. Choropleth mapping was used to visualise volumes of boardings at local authority level (Harries, 1999) and visualisations were produced using IDW interpolation (Smith et al., 2007) to depict where Zip boardings are greatest; techniques not used before for exploring Zip card data. Using this method highlighted specific locations within local authorities in which Zip boardings were clustered. Weekday outputs typically pinpoint school or town centre locations, whilst at the weekend, town centres and popular London entertainment venues appear more prominently.

Analysis at this level demonstrated the potential for transport data to identify when and where young people are spending their time, but was largely limited in its ability to input meaningfully into safeguarding processes. Analysis at bus stop, however, had more safeguarding potential.

\section{Drilling down: Bus-stop/road segment analysis 1}

An initial attempt to map approximately 19,000 bus stops at the pan-London level: sheer quantity made the resulting maps unusable. At a ward or local authority level however, mapping Zip boarding totals by bus stop proved useful. Depending on the purpose of analysis, it was possible to isolate and visualise those bus stops within a user-defined area that had either the lowest or highest volume of Zip boardings at any particular time. 
The available bus stop data was joined to the OpenStreetMap (OSM) road network layer, which summed and appended the boarding totals at each bus stop to their nearest road segment. This approach is a means through which to take a view of where Zip boardings are occurring, and in what volumes, at any user-defined level (exemplified in Figure 3).

\section{INSERT FIGURE 3}

Applied at a local level, this approach identifies and visualises high concentration corridors for Zip journeys, opening-up the potential to target safeguarding interventions at particular 'corridors' of travel. Taking one local authority, 'Area B', as an example, all weekday Zip boardings across the whole period, between the hours of 15:00-17:59, were queried and set up within ArcGIS for analysis. At the road segment level, specific corridors of travel were visible along with the total number of Zip boardings occurring on those segments. As a result of the timeframe selected, a large number of these segments appeared near local schools. However, it was also possible to identify segments in areas away from the busier schools and town centres where Zip boardings were occurring during school leaving hours. Analysing this data at the bus stop level identified a cluster of high volume Zip boarding stops towards the north of the local authority, bordering a neighbouring local authority. These findings indicated that the same stops and corridors were being used by young people from a cluster of schools and potential cross-border journeys were being made,. This resulted in young people from different areas and schools converging on particular routes and at specific stops within the area; a contextual dynamic that has emerged in case reviews (Author A, 2015) and one that young people have perceived as a risk to their safety (outlined previously). Of the 500 (approximate) bus stops in Area B only one particular cluster/ corridor and five additional stops appear to be used by large numbers of young people. This creates an opportunity for the local safeguarding partnership to identify and intelligently intervene with specific locations where young people spend their time.

\section{The potential for identifying safeguarding concerns}

The potential for using the approaches outlined thus far to inform or direct safeguarding practices are best illustrated through a case study. 'Area C' is the focus of this case study and results are described rather than illustrated through the maps produced in the research to maintain anonymity.

Data was queried to return Zip boardings occurring on a specific day and hour (Wednesday $29^{\text {th }}$ June, 01:00-01:59) within 'Area C', which provided a more detailed understanding of young people's use of the bus network at a specific time of day. Exploring data on journeys made during a weekday night was particularly important in relation to safeguarding: it is largely uncommon for young people to be travelling, for safe and legitimate reasons, on public transport in the middle of the night on a weekday during school term time.

When visualised on a map, it was possible to identify four bus stops in 'Area C' where there had been in excess of 10 boardings with Zip cards in that one-hour window. One of these bus stops was located outside a National Rail station and therefore was likely to feature young people returning home with family members following trips, for example. However the other three bus stops were located in largely residential areas, on different bus route 
corridors, and were dispersed across Area C. When discussed with community safety professionals within TfL they corroborated the view that with the exception of the one stop, the other bus stops are not typically busy in the early hours. A number of questions arise, therefore, from these results. Why were young people travelling at that time of night? Where were they going to or coming from? Were any of their journeys related to significant safeguarding concerns such as exploitation or other factors that can lead a young person to go missing overnight?

By identifying that Zip boardings are occurring in the early hours of this specific weekday, the findings of this case study provides a starting-point for further multi-agency and singleagency investigation. If this journey data was linked to problem profiles generated by social care, policing or community safety analysts concerned with exploitation in Area C, for example, they may corroborate or extend local knowledge about locations where young people are vulnerable to abuse or transport patterns associated to exploitation.

Analysis of journeys in a number of areas during this exploratory study identified young people travelling during the night in largely residential corridors. There is potential therefore, for transport data to feed into problem profiles to corroborate, correct or develop information held by analysts about localities in which young people are vulnerable to abuse.

\section{Discussion - Implications for policy and practice}

Contextual Safeguarding theory posits that individuals who oversee, manage or use the public and social spaces in which young people spend their time have a role in keeping them safe when they are there (Author A et al., 2016; Author A, 2017a; Author A, 2017b). Recent policy concerns about the welfare of young people on trains, in taxis and when using local businesses has triggered debates and recommendations about the safeguarding role/s of those who manage commercial, public-space. This study has used bus travel data held by TfL to explore the potential role that could be played by transport services within a Contextual Safeguarding agenda. The data collected by TfL could be used to inform the way that local partnerships identify and intervene with contexts in which young people are vulnerable to harm, as well as inform the way that TfL provide services to young people who use their bus network. The role of local partnerships is critical here: when analysed in isolation of wider local practices or intelligence, the data explored here cannot be used to draw conclusions about the welfare of young people.

In terms of enhancing the work of multi-agency safeguarding partnerships, Zip card data and the analysis of it presented in this paper - can be used to inform proactive positive interventions to create safe spaces for young people, as well as identify and disrupt those contexts in which they encounter harm. . In relation to the former point, if large numbers of young people regularly use a particular space at a set time it is important that their encounters in this space are safe. Safeguarding partnerships could draw upon the data presented in this paper to identify opportunities for positive interventions which maximise the likelihood of safety at these times, beyond the deployment of police into busy areas.

In terms of direct safeguarding interventions, being able to identify locations where young people are boarding public transport during the night or during the school day is significant. Not all young people are reported missing from home, and when young people aren't in 
school the 'truancy' may be responded to but not necessarily the factors that are driving the disengagement from school. Whether children are missing from home or school it is not always evident where they have been and young people will not always disclose this information to practitioners. Transport data, even at the level explored in this paper, could direct partnerships to monitor particular stops being used at times that are unusual and through this process ascertain whether young people: are there; travelling in groups or alone, and; the specific locations they are travelling to or from are safe (home, park etc.). As such TfL would not necessarily have to disclose individual level data .A partnership assessmap the trends in transport data against other information they hold, collate it, use it to identify locations where young people are frequenting at night and identify whether these locations pose a risk to young people's welfare.

In addition to informing the work of safeguarding partnerships, this data has the potential to advance the involvement of TfL and other transport providers in creating contextual safeguarding systems in local areas. In order for social care teamsto fully implement and explore the impact of contextual safeguarding they require partnerships with services that operate in, and manage, the public spaces in which young people encounter harm (Author A, et al., 2016). Multi-agency data could be used by transport providers to understand how and when young people use their services, and potential vulnerable contexts served by a bus route which may require additional attention from those who drive, inspect or monitor those bus routes. In addition, by engaging with local partnerships, transport providers may be in a better position to contextualise the data that they already hold. For example, a multiagency partnership may already have concerns about a residential property where young people are being sexually exploited. This information could explain why there are an increased number of young people using the bus network in a particular corridor during the night, and trigger TfL, or their drivers, to be alert to the welfare of young people on that particular route.

As a result Zip card data has the potential to inform:

- How young people's movement around, and safety within, a local area is understood by professionals, particularly their use of transport outside usual times of day

- The targeting of positive interventions into areas where large numbers of young people are spending time socialising, particularly after school

- Local area profiling activities which are used by partnerships to identify contexts in which young people are vulnerable to abuse

- How transport providers deliver services to young people

At this stage this potential is limited to data on journeys made by ten or more young people within an hour. However, even at the level explored in this paper Zip card data has evidenced potential for informing practices concerned to safeguard young people in public spaces. In order to test the proposals made in this paper TfL need to engage with local contextual safeguarding partnerships who are in a position to utilise the information that can be provided by Zip card data.

While this potential was identified for London's bus network the findings, and this discussion, are applicable to all transport providers more widely. By testing the approaches explored in this paper to identify and respond to safeguarding concerns in a local area the potential 
presented in this paper can be unlocked - contributing to advancement of contextual safeguarding theory and practices.

\section{Works Cited}

Author A 2015.

Author A 2016.

Author A 2017.

Author A 2015.

Author A and Anon, 2018 forthcoming

Aldridge, J., Shute, J., Ralphs, R. \& Medina, J., 2011. Blame the Parents? Challenges for Parent-Focused Programmes for Families of Gang-Involved Young People. Children and Society, Volume 25, p. 371-381.

Anderson, E., 1999. Code of the street: Decency, violence, and the moral life of the inner city. New York: WW Norton.

Bagchi, M. and White, P.R., 2005. The potential of public transport smart card data, Transport Policy, 12, pp. 464-474.

Barter, C., 2009. In the Name of Love: Partner Abuse and Violence in Teenage Relationships. British Journal of Social Work, Volume 39, p. 211-233.

Beckett, H. et al., 2013. It's wrong but you get used to it: A qualitative study of gangassociated sexual violence towards, and sexual exploitation of, young people in England , London: Office of the Children's Commissioner.

Burton, S., 2008. A problem-oriented policing approach to tackling youth crime and antisocial behaviour on London's buses. London: Transport for London.

Catch 22, 2013. The role of the family in facilitating gang membership, criminality and exit, London: Catch 22.

Coleman, J., 2011. The Nature of Adolescence. Fourth ed. Oxon: Routledge.

D'Arcy, K. \& Thomas, R., 2016. Nightwatch: CSE in Plain Sight, Luton: University of Bedfordshire.

De Smith, M.J., Goodchild, M.F. and Longley, P.A., 2007. Geospatial Analysis: A Comprehensive Guide to Principles, Techniques and Software Tools. Leicester: Matador.

GLA Intelligence, 2012. 2011 Census first results: London boroughs' populations by age and sex, London: Greater London Authority. 
Goodman, A., Jones, A., Roberts, H., Steinbach, R. and Green, J., 2014. 'We Can All Just Get on a Bus and Go': Rethinking Independent Mobility in the Context of the Universal Provision of Free Bus Travel to Young Londoners, Mobilities, 9(2), pp. 275-293.

Hackett, S., 2014. Children and young people with harmful sexual behaviours. Dartington: Research in Practice.

Hughes-Jones, L. \& Roberts, S., 2015. Closing the Gap: Confronting the Problem of Hotels as Venues for Child Sexual Exploitation. The Howard Journal of Criminal Justice, 54(4), pp. 336-351

Jones, A., 2010. Free for some? Setting the context for the 'On the Buses' study, Occasional Papers in Transport and Health (1). London: LSHTM.

Jones, A., Goodman, A., Roberts, H., Steinbach, R. and Green, J., 2013. Entitlement to concessionary public transport and wellbeing: A qualitative study of young people and older citizens in London, UK, Social Science \& Medicine, 91, pp.202-209.

Liebenberg, L., Ungar, M. \& Ikeda, J., 2015. Neo-Liberalism and Responsibilisation in the Discourse of Social ServiceWorkers. The British Journal of Social Work, Volume 45, pp. 1006-1021.

Lynn News, 2016. Safeguarding Taxi Training to be Essential. [Online] Available at: http://www.lynnnews.co.uk/news/safeguarding-taxi-training-to-beessential-1-7703439

[Accessed 30. 09. 2017].

Newton, A.D. (2014) Crime on Public Transport. In: Encyclopaedia of Criminology and Criminal Justice. London: Springer, 709-720.

Newton, A.D., Partridge, H. \& Gill, A. (2014) Above and below: measuring crime risk in and around underground mass transit systems, Crime Science: An Interdisciplinary Journal, 3(1), pp. 1-14.

Office of National Statistics, 2013. Crime in England and Wales, Year Ending March 2013. [Online]

Available at: http://www.ons.gov.uk/ons/rel/crime-stats/crime-statistics/period-endingmarch-2013/stb-crime--period-ending-march-2013.html\#tab-Crime-experienced-bychildren-aged-10-to-15

[Accessed 03. 12. 2015].

Parton, N., 2014. The Politics of Child Protection. TBC: Palgrave.

Sidebotham, P. et al., 2016. Pathways to harm, pathways to protection: a triennial analysis of serious case reviews 2011 to 2014: Final report, London: DfE.

Smallbone, S., Rayment-Mchuhgh, S. \& Smith, D., 2013. Youth Sexual Offending: Context, Good ENough Lives, and ENgaging with a Wider Prevention Agenda. International Journal of Behavioral Consultation and Therapy, 8(3-4), pp. 49-54. 
Smith, C., Quercia, D. and Capra, L., 2013. Finger On The Pulse: Identifying Deprivation Using Transit Flow Analysis, Proceedings of the 2013 conference on Computer supported cooperative work, p683-692.

Squires, P. \& Goldsmith, C., 2011. Bullets, Blades and Mean Streets: Youth Violence and Criminal Justice Failure. In: Children Behaving Badly? Peer Violence Between Children and Young People. West Sussex: John Wiley and Sons Ltd, pp. 199 - 216.

TfL, 2015. Travel in London: Understanding our diverse communitie, London: Transport for London.

TfL ,2016a. Zip Oyster photocards, Available at: https://tfl.gov.uk/fares-and-payments/travelfor-under-18s/zip-oyster-photocards [Accessed 05.07.2016].

TfL, 2016b. Publications and Reports: Buses, Available at: https://tfl.gov.uk/corporate/publications-and-reports/buses [Accessed 05.07.2016].

TfL, 2016c. Buses, Available at: https://tfl.gov.uk/corporate/about-tfl/what-we-do/buses [Accessed 05.07.2016].

Transport Select Committee, 2014. Security on the Railways, London: The Stationary Office.

Warr, M., 2002. Companions in crime: The social aspects of criminal conduct. Cambridge: Cambridge University Press.

World Health Organisation , 2014. Inspire: Seven Strategies for Ending Violence Against Children, s.I.: WHO. 